microsurgery and in $3(19 \%)$ with endovascular surgery. Treatment-related neurological morbidity occurred in $2(7 \%)$ patients, 1 in each group, and no patient died as a result of surgery. (Sanai N, Quinones-Hinojosa A, Gupta NM, et al. Pediatric intracranial aneurysms: durability of treatment following microsurgical and endovascular management. J Neurosurg (2 Suppl Pediatrics) Feb 2006;104:82-89). (Reprints: Michael T Lawton MD, Department of Neurological Surgery, University of California, 505 Parnassus Avenue, M-780C, San Francisco, CA 94143).

COMMENT. Diagnostic risk factors for intracranial aneurysm in children include symptoms and signs of an acute mass lesion, subarachnoid hemorrhage, chronic headaches, a history of head trauma, and certain medical comorbidities, including polycystic kidneys, aortic coarctation, and bleeding disorders. The aneurysms in children are usually large and located anteriorly at the internal carotid bifurcation or posteriorly; in adults they are small, saccular and located on the circle of Willis. Treatment of pediatric aneurysms by microsurgery may be more effective than balloon occlusion, and the long-term benefits more durable.

Heros RC, in an editorial, notes the differences in the current and previous reviews of pediatric intracranial aneurysms compared to adults (J Neurosurg (2 Suppl Pediatrics) 2006;104:77-88). Treatment is more successful in children, especially with collaboration of pediatric neurosurgeon and neurovascular surgeon, a practice favored by Dr Sanai and colleagues.

\title{
NEONATAL PORENCEPHALY, ADULT STROKE, AND COLLAGEN IV A1 MUTATION
}

The relation of leukoencephalopathy, lacunar infarcts, micro- and macro-bleeds to a defect in collagen IV A1 gene was examined in a family with the mutation and autosomal dominant porencephaly followed at VU University Medical Center, Amsterdam, the Netherlands. Porencephaly was diagnosed in the mother at age 24 years, while her 2 children had symptoms and signs of porencephaly in infancy. The mother developed recurrent strokes beginning at age 42 years. All 3 patients had leukoencephalopathy. MRI showed lacunar infarcts, and micro- and macro-bleeds. Electron microscopy of skin vessels showed interruptions and thickening of the basement membrane. A heterogeneous mutation in the collagen IV A1 gene, a component of the vascular basement membrane, was found in all 3 patients, but was absent in the father and in 192 matched Dutch controls. This mutation is a risk factor for a microangiopathy, resulting in perinatal hemorrhage and porencephaly, leukoencephalopathy, and later onset ischemic and hemorrhagic strokes. (van der Knaap MS, Smit LME, Barkhof F, et al. Neonatal porencephaly and adult stroke related to mutations in collagen IV A1. Ann Neurol March 2006;59:504-511). (Respond: Dr van der Knaap, Department of Child Neurology, VU University Medical Center, PO Box 7057, 1007 MB Amsterdam, the Netherlands).

COMMENT. Porencephaly, a term first coined by Heschl in 1859 to designate a congenital defect extending from the surface of the brain to the lateral ventricle, was later defined as any cavity within the brain tissue, with or without extension to the ventricle or subarachnoid space, of prenatal or postnatal origin (Norman RM. In Greenfield's 
Neuropathology. Baltimore, Williams \& Wilkins, 1963). Yakovlev and Wadsworth (1946) described schizencephalic porencephalies of developmental origin and encephaloclastic porencephalies caused by destruction of cerebral tissue. A wide variety of etiological factors and clinical findings are reported (Mednick JP, Jerva MJ, Millichap JG. Trans Am Neur Assoc 1966;301-303). Hemorrhagic infarction following a germinal matrix hemorrhage in a preterm infant is a frequent destructive cause. Other causes include trauma, vasculopathy secondary to maternal cocaine abuse or congenital infections such as cytomegalic inclusion disease, bleeding disorders, including factor V Leiden and collagen IV A1 mutation with microangiopathy, as in familial autosomal dominant porencephaly, described in the above report.

\section{VASCULAR ABNORMALITIES IN ALTERNATING HEMIPLEGIA}

Skin and/or muscle biopsies in 4 patients, ages 18 months, 8, 9, and 16 years, with alternating hemiplegia of childhood (AHC) were examined by electron microscopy and compared with healthy controls in a study at University Hospital, Lille, France. Vascular abnormalities present in both skin and muscle small vessels included endothelial vacuoles, intracytoplasmic vacuoles in vascular smooth muscle cells (VSMCs) in the tunica media, apoptotic nuclei, and isolation of VSMCs from neighboring cells. A primary or secondary vascular pathophysiology is suggested for AHC. (Auvin S, Joriot-Chekaf S, Cuvellier JC, et al. Small vessel abnormalities in alternating hemiplegia of childhood. Neurology February (2 of 2) 2006;66:499-504). (Reprints: Dr S Auvin, Service de Neurologie pediatrique, Hopital Roger Salengro, Boulevard du Pr J Leclercq, 59037 Lille Cedex, France).

COMMENT. AHC is characterized by 3 phases; 1) abnormal eye movements and dystonic episodes; 2) episodic hemiplegia and developmental delay; and 3) persistent neurologic deficits. Onset is before 18 months of age, and symptoms resolve during sleep. Formerly ascribed to a migraine equivalent, an epilepsy, or movement disorder, the present evidence suggests a neurovascular mechanism, similar to the cerebral autosomal dominant arteriopathy with subcortical infarcts and leukoencephalopathy (CADASIL).

\section{INTRACRANIAL NEOPLASMS}

\section{SUPRASELLAR GERMINOMA AND GROWTH RETARDATION}

Three patients, ages 9, 12, and 13 years ( 1 boy and 2 girls), diagnosed with intracranial germinoma are reported from University Children's Hospital Homburg, Germany. Presenting symptoms and signs prompting an MRI were nausea, vomiting, strabismus, and intermittent headache for 1 year in case 1, migraine in case 2, and a 3-year history of growth retardation in case 3. Patients 1 and 2 also had a history of growth retardation for 2 years. MRI showed tumors in the pituitary region in cases 1 and 2 , and a thickened pituitary stalk in case 3. Clinical and laboratory findings showed panhypopituitarism, subclinical diabetes insipidus and hypothyroidism, and growth hormone deficiency in cases 1,2, and 3, respectively. CSF levels of Beta-human chorionic gonadotrophins (B-hCG) were not elevated, and diagnosis of germinoma was confirmed by 